\title{
RESEARCH
}

Open Access

\section{Moderate SMFs attenuate bone loss in mice by promoting directional osteogenic differentiation of BMSCs}

\author{
Guilin Chen ${ }^{1 \dagger}$, Yujuan Zhuo ${ }^{1 \dagger}$, Bo Tao ${ }^{2 \dagger}$, Qian Liu', Wenlong Shang ${ }^{1}$, Yinxiu Li ${ }^{1}$, Yuhong Wang ${ }^{1}$, Yanli Li ${ }^{1}$,
} Lei Zhang ${ }^{3}$, Yanwen Fang ${ }^{4}$, Xin Zhang ${ }^{3}$, Zhicai Fang ${ }^{4}$ and Ying Yu ${ }^{{ }^{*}}$

\begin{abstract}
Background: Osteoporosis is a common metabolic bone disease without effective treatment. Bone marrow-derived mesenchymal stem cells (BMSCs) have the potential to differentiate into multiple cell types. Increased adipogenic differentiation or reduced osteogenic differentiation of BMSCs might lead to osteoporosis. Whether static magnetic fields (SMFs) might influence the adipo-osteogenic differentiation balance of BMSCs remains unknown.

Methods: The effects of SMFs on lineage differentiation of BMSCs and development of osteoporosis were determined by various biochemical (RT-PCR and Western blot), morphological (staining and optical microscopy), and micro-CT assays. Bioinformatics analysis was also used to explore the signaling pathways.

Results: In this study, we found that SMFs (0.2-0.6 T) inhibited the adipogenic differentiation of BMSCs but promoted their osteoblastic differentiation in an intensity-dependent manner. Whole genomic RNA-seq and bioinformatics analysis revealed that SMF (0.6 T) decreased the PPARY-mediated gene expression but increased the RUNX2-mediated gene transcription in BMSCs. Moreover, SMFs markedly alleviated bone mass loss induced by either dexamethasone or all-trans retinoic acid in mice.
\end{abstract}

Conclusions: Taken together, our results suggested that SMF-based magnetotherapy might serve as an adjunctive therapeutic option for patients with osteoporosis.

Keywords: Bone marrow-derived mesenchymal stem cell, Static magnetic field, Osteoporosis, Osteogenic differentiation, Magnetic therapy

\footnotetext{
* Correspondence: yuying@tmu.edu.cn

${ }^{\dagger}$ Guilin Chen, Yujuan Zhuo, and Bo Tao contributed equally to this work and should be regarded as joint first authors.

'Department of Pharmacology, Tianjin Key Laboratory of Inflammatory Biology, The Province and Ministry Co-sponsored Collaborative Innovation Center for Medical Epigenetics, School of Basic Medical Sciences, Tianjin Medical University, Tianjin 300070, China

Full list of author information is available at the end of the article
}

(C) The Author(s). 2020 Open Access This article is licensed under a Creative Commons Attribution 4.0 International License, which permits use, sharing, adaptation, distribution and reproduction in any medium or format, as long as you give appropriate credit to the original author(s) and the source, provide a link to the Creative Commons licence, and indicate if changes were made. The images or other third party material in this article are included in the article's Creative Commons. licence, unless indicated otherwise in a credit line to the material. If material is not included in the article's Creative Commons licence and your intended use is not permitted by statutory regulation or exceeds the permitted use, you will need to obtain permission directly from the copyright holder. To view a copy of this licence, visit http://creativecommons.org/licenses/by/4.0/. The Creative Commons Public Domain Dedication waiver (http://creativecommons.org/publicdomain/zero/1.0/) applies to the data made available in this article, unless otherwise stated in a credit line to the data. 


\section{Background}

Osteoporosis is a common bone and metabolic disease, characterized by reduced bone formation and increased fat accumulation in the bone marrow space, leading to decreased bone mineral density (BMD) and increased bone fractures [1]. As such, it is reported to be responsible for more than 1.5 million fractures worldwide annually [2]. Both adipose-derived stem cells (ASCs) and bone marrow-derived mesenchymal stem cells (BMSCs) are multipotent progenitor cells with the potential to differentiate into various mature cell types, including osteoblasts, chondrocytes, and adipocytes [3, 4], which have been utilized extensively in the research field of bone tissue regeneration. Despite higher proliferative capacity for ASCs, BMSCs display more potential for osteogenic and chondrogenic differentiation $[5,6]$. Disrupting the dynamic balance between adipogenic and osteogenic differentiation of BMSCs, such as increased differentiation toward adipocytes or reduced differentiation toward osteoblasts, has been shown to cause osteoporosis and other bone and metabolic diseases [7, 8]. As pleiotropic drugs, metformin and rapamycin have been reported to promote bone generation and improve bone density by increasing osteogenic differentiation potential of BMSCs $[9,10]$. Moreover, physical activities have also been found to induce mobilization of stem cells and promote bone regeneration $[11,12]$. However, the mechanisms behind the fine-tuned regulation of the commitment of the BMSC lineage to differentiate to osteoblasts versus adipocytes remain elusive.

Humans are exposed to the naturally occurring magnetic fields of the earth. Lack of exposure to natural magnetic fields, such as staying in space, has been reported to cause insomnia, fatigue, depression, and increased predisposition for osteoporosis in humans [13], suggesting that the magnetic field might be beneficial for physiological function and human health. Accumulated evidence has shown that static magnetic fields (SMFs) might act on a variety of potential targeting organs and tissues, exerting favorable physiological effects on many biological systems, including suppression of inflammatory reactions [14], reduction of edema formation [15], improvement of microcirculation and blood flow [16, 17], relief of osteoarthritis-induced pain [18], and facilitation of wound healing [19]. Therefore, magnetotherapy has been officially approved by the US Food and Drug Administration (FDA) for the treatment of pain and edema in superficial soft tissues for orthopedic applications [20]. Moreover, moderate-intensity SMF has been shown to enhance repair after cartilage damage and accelerate the formation of new bone tissue in rat models, by promoting extracellular matrix deposition [21, 22]. SMF treatment has been reported to increase BMD of osteoporotic lumbar vertebrae in ovariectomized rats
[23] and prevent the architectural deterioration and strength reduction of bones in streptozotocin-treated diabetic rats by enhancing osteogenic differentiation [24]. These observations strongly suggest that SMF might help prevent and treat osteoporosis. However, whether SMFs might participate in the reciprocal regulation between adipocyte and osteoblast differentiation of BMSCs and the subsequent control of the adipoosteogenic balance remains to be determined.

In the present study, we stimulated BMSCs during adipogenic and osteogenic differentiation with different intensities of SMFs $(0 \mathrm{~T}, 0.2 \mathrm{~T}, 0.4 \mathrm{~T}$, and $0.6 \mathrm{~T})$, and found SMFs promoted osteoblastic differentiation, but inhibited adipogenic differentiation of BMSCs in an intensity-dependent manner. Whole genomic RNA-seq analysis demonstrated SMFs decreased PPAR $\gamma$-driven gene expression while increased RUNX2-driven gene transcription in BMSCs. Moreover, SMFs markedly alleviated bone mass loss induced by either dexamethasone (Dex) or all-trans retinoic acid (ATRA) in mice. Thus, our study reveals moderate intensity SMFs may serve as an adjunctive therapeutic option for osteoporosis.

\section{Methods \\ Animals}

Wild-type C57BL/6J mice were purchased from GemPharmatech Co. Ltd. and were housed in specific pathogen-free animal facilities of the Tianjin Medical University. Accordingly, 8-10-week-old male mice were used in this study. All animal experiments were performed in accordance with the Guidelines of the Institutional Animal Care and Use Committee of Tianjin Medical University.

\section{Reagents}

CD29-APC, CD105-PE-Cy7, Sca1-FITC, and c-kit-APC antibodies were purchased from Thermo Fisher Scientific (eBioscience), while CD44-Percp5.5, CD90-BV421, CD34-PE, CD45-APC, and CD11b-FITC antibodies were obtained from Biolegend. Oil red $\mathrm{O}(\mathrm{ORO})$, alizarin red $\mathrm{S}$ (ALS), all-trans retinoic acid (ATRA), dexamethasone (Dex), and mineral oil were purchased from SigmaAldrich.

\section{Moderate SMF exposure system}

For the creation of the SMF exposure system, gradient permanent neodymium magnets $(130 \times 110 \times 60 \mathrm{~mm})$ were assembled beneath the cell plates to expose the cultures to north fields (N; Fig. 1a). The distribution of the representative SMF $(0.6 \mathrm{~T})$, measured using a digital Tesla meter (HT20), was shown in Fig. 1b, c. For mouse exposure, the magnetic or nonmagnetic sandwich plates $(230 \times 130 \times 15 \mathrm{~mm})$, in which 24 magnets $(10 \mathrm{~mm}$ diameter and $15 \mathrm{~mm}$ thickness) were inserted with alternating 

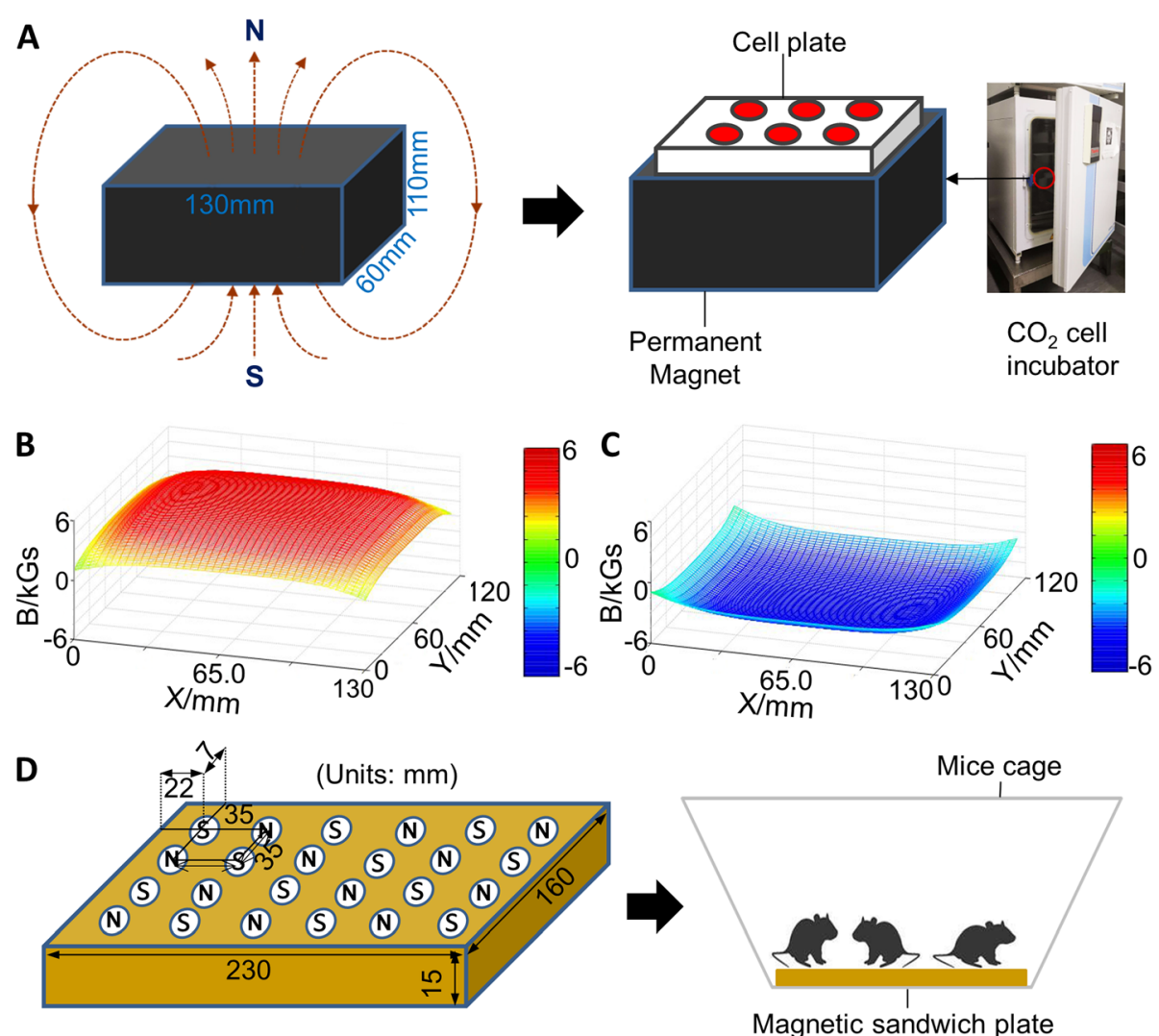

E $2 \mathrm{~cm}$ above sham control plate

F $2 \mathrm{~cm}$ above the ' $0.6 \mathrm{~T}$ ' magnetic plate
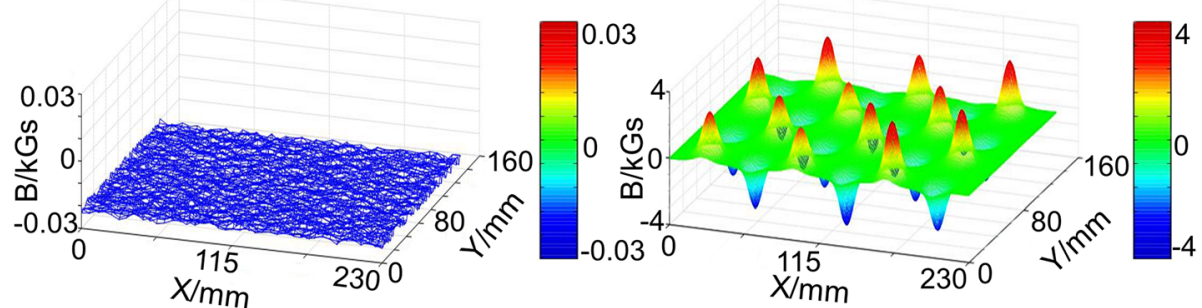

Fig. 1 Schematic diagram of the static magnetic field (SMF) systems. a A permanent magnet assembled beneath the cell plates to generate an SMF environment. $\mathbf{b}, \mathbf{c}$ Intensity distribution of SMF of the $130 \times 110 \times 60 \mathrm{~mm}$ magnet (0.6 T shown here) for the cell exposure experiments. $\mathbf{d}$ The magnetic or nonmagnetic sandwich plates $(230 \times 130 \times 15 \mathrm{~mm})$, in which 24 magnets $(10 \mathrm{~mm}$ diameter and $15 \mathrm{~mm}$ thickness) were inserted with alternating magnetic poles (north or south; $N$ or S) facing up, were placed beneath the cages in which mice were housed. e-f The distribution of SMF intensity of the $230 \times 130 \times 15 \mathrm{~mm}$ control magnetic equipment $(0 \mathrm{~T} ; \mathbf{e})$ and $0.6 \mathrm{~T}$ magnetic sandwich plate (f) used for the animal study

magnetic poles (north or south; $\mathrm{N}$ or $\mathrm{S}$ ) facing up, were placed beneath the mouse cages and separated by spaced holes (Fig. 1d) as previously reported [19, 25]. The SMF intensity distribution of control and $0.6 \mathrm{~T}$ magnetic sandwich plates were shown in Fig. 1e and Fig. 1f, respectively, as measured by a space magnetic field measuring instrument (FE-2100RD).

\section{Cell culture}

BMSCs were isolated from femoral bones of male mice (4-6 week-old), as previously reported [26, 27]. At passage 3, BMSCs were subjected to purification by flow cytometry through the identification of CD29, CD44, CD90, CD105, and Sca-1 positive surface markers and $\mathrm{CD} 11 \mathrm{~b}, \mathrm{CD} 34, \mathrm{CD} 45$, and c-kit negative surface markers, as shown in sFig. 1 . Then, BMSCs were subjected to adipogenic and osteogenic differentiation using the respective induction media.

\section{Adipogenic differentiation assay}

Isolated BMSCs were maintained in $\alpha$-MEM containing $10 \%$ fetal bovine serum (16000-044, Gibco, USA), 100 U/ 
$\mathrm{mL}$ penicillin, and $0.1 \mathrm{mg} / \mathrm{mL}$ streptomycin (C125CS, NCM Biotech). For adipogenic differentiation, BMSCs were grown in basal medium supplemented with $1 \mu \mathrm{M}$ Dex (Sigma-Aldrich), $0.5 \mathrm{mM}$ 3-isobutyl-1-methylxanthine (Sigma-Aldrich), $10 \mu \mathrm{g} / \mathrm{mL}$ insulin (Sigma-Aldrich), and $1 \mu \mathrm{M}$ rosiglitazone (Sigma-Aldrich) for 14 days. The culture medium was replaced every other day. Fat droplet formation was visualized by ORO staining and quantified using the Image J software.

\section{Osteogenic differentiation assay}

BMSCs were grown in basal medium until appropriate cell confluence (approximately 70\%). For osteogenic differentiation, BMSCs were cultured in osteogenic induction medium containing $50 \mathrm{mM}$ ascorbate-2phosphate, $0.1 \mathrm{mM}$ dexamethasone, and $10 \mathrm{mM} \beta$ glycerol phosphate for 21 days. The culture medium was changed every third day. After osteogenic differentiation for 3 days, cultured BMSCs were fixed with $70 \%(\mathrm{v} / \mathrm{v})$ ethanol and incubated in $0.25 \%(\mathrm{w} / \mathrm{v})$ naphthol AS-BI phosphate solution and 0.75\% (w/v) Fast Blue BB in 0.1 $M$ Tris buffer before alkaline phosphatase (ALP) staining. A commercial ALP activity kit (Sigma-Aldrich) was used to assess the ALP activity of differentiated cells according to the manufacturer's instructions, following normalization by total cell protein. At the end of differentiation, alizarin red S (ALS) staining was performed to evaluate the mineralization of the cell matrix.

\section{Histological analysis}

Paraffin-embedded femurs were sectioned $(5 \mu \mathrm{m})$, deparaffinized, and then stained with hematoxylin and eosin (H\&E) for morphological analysis. For immunohistochemistry staining, deparaffinized and dehydrated tissue sections were re-hydrated before being subjected to antigen retrieval, and then blocked with diluted normal serum for at least $1-1.5 \mathrm{~h}$ at $25^{\circ} \mathrm{C}$ to eliminate nonspecific binding. The slides were incubated with primary antibodies against osteocalcin (OCN) (1:300; Abcam) overnight at $4{ }^{\circ} \mathrm{C}$. After careful washing, the sections were incubated with horseradish peroxidase conjugates to detect positive signals, followed by counterstaining with hematoxylin (Sigma-Aldrich). Slides incubated with polyclonal rabbit IgG (Abcam) served as negative controls. Pictures were captured and monitored using a Leica Microsystems microscope (Leica Microsystems Ltd.), while the ImageJ software (National Institutes of Health) was used to analyze the number or area of adipocytes and osteoblasts.

\section{Real-time quantitative PCR}

Total mRNA was extracted from BMSCs grown in adipogenic or osteogenic medium using TRIzol reagent (Invitrogen) and reverse-transcribed to cDNA using a
Reverse Transcription Reagent kit (Takara Bio Inc.) according to the manufacturer's protocol. The resulting cDNA was amplified using the Real-Time PCR system (LightCycler 480 II, Roche) with 40 cycles. Sequences of primers for target genes are presented in Supplementary Table 1. The mRNA levels of the specific genes were normalized to that of a reference gene ( $\beta$-actin) within the samples.

\section{Western blotting}

After being cultured in adipogenic or osteogenic medium, BMSCs were harvested and lysed with RIPA (Solarbio). Protein concentrations were quantified using a BCA Protein Assay Kit (Thermo Fisher Scientific). Equal amounts of protein were denatured and resolved by $10 \%$ sodium dodecyl sulfate-polyacrylamide gel electrophoresis, transferred to polyvinylidene fluoride membranes (Millipore), incubated with 5\% skimmed milk (Biofath) for $1-1.5 \mathrm{~h}$ at $25^{\circ} \mathrm{C}$, and then incubated overnight at $4{ }^{\circ} \mathrm{C}$ with primary antibodies. Primary antibodies were diluted as follows: PPAR $\gamma$ (1:500; Santa Cruz Biotechnology), Fabp4 (1:1000; Abcam), Runx2 (1:1000; Cell Signaling Technology), and ALP (1:1000; Santa Cruz Biotechnology). $\beta$-Actin (1:5000; Cell Signaling Technology) or $\alpha$-Tubulin (1:10,000; Sungene Biotech) was used as loading control. Consecutively, the membranes were incubated with horseradish peroxidase-conjugated secondary antibodies (1:2000; Cell Signaling Technology) dissolved in blocking buffer for $2 \mathrm{~h}$ at $25^{\circ} \mathrm{C}$. Blots were detected using an enhanced chemiluminescent reagent kit (Thermo Fisher Scientific).

\section{RNA-seq}

BMSCs plated in $10 \mathrm{~cm}$ dishes were exposed on a control iron plate $(0 \mathrm{~T})$ or a magnetic plate $(0.6 \mathrm{~T})$ for $48 \mathrm{~h}$ respectively. Then, BMSCs were washed by cold PBS for 3 times and then lysed by using Trizol at room temperature. Samples were sent to Novogene on dry ice for library preparation and sequencing. A total amount of $3 \mathrm{mg}$ RNA per sample was used as input material for the RNA sample preparations. Sequencing libraries were generated using NEBNext UltraTM RNA Library Prep it for Illumina (NEB, USA) following manufacturer's recommendations and index codes were added to attribute sequences to each sample. The clustering of the indexcoded samples was performed on a cBot Cluster Generation System using TruSeq PE Cluster Kit v3-cBot-HS (Illumia) according to the manufacturer's instructions. After cluster generation, the library preparations were sequenced on an Illumina platform and $150 \mathrm{bp}$ pairedend reads were generated. $\mathrm{R}$ software version GSEA and package fgsea were used for cellular pathway analysis including Hallmark gene sets and GO gene sets. 


\section{Microcomputed tomography (micro-CT) scan}

Femurs of the same side were dissected from mice treated with ATRA for 21 days [28] or treated with Dex for 3 months [29] and fixed with 4\% paraformaldehyde for more than $24 \mathrm{~h}$. Then, the samples were scanned and analyzed using a micro-CT System (Skyscan 1172, Bruker) with a high resolution (voltage $50 \mathrm{kV}$; current $201 \mu \mathrm{A}$; resolution $12 \mathrm{~mm} /$ pixel), as reported [30]. The NRecon image reconstruction software (Bruker), CTVol 3D model visualization software (Bruker), and CTAn data analysis software (Bruker) were used to analyze the parameters of the trabecular bones. For distal femurs, regions of interest were selected for the analysis of BMD, trabecular bone volume per tissue volume (Tb.BV/TV), trabecular separation (Tb.Sp), trabecular number (Tb.N), and trabecular thickness (Tb.Th).

\section{Statistical analysis}

Data were analyzed using GraphPad Prism version 6.0 and are presented as the mean \pm standard error of the mean. Two-tailed unpaired Student's $t$ test or one-way ANOVA with Bonferroni post hoc analyses were applied when appropriate for multiple comparisons. A value of $P<0.05$ was considered statistically significant.

\section{Results}

\section{Moderate SMFs inhibited adipogenic differentiation of murine BMSCs}

To investigate the effect of SMFs on the adipogenic differentiation of BMSCs, BMSCs grown in adipogenic medium were exposed to different intensities of moderate SMFs $(0,0.2,0.4$, and $0.6 \mathrm{~T})$. ORO staining showed that SMFs significantly inhibited lipid-droplet formation in BMSCs in adipogenic medium in an intensitydependent manner (Fig. 2a, b). The expression of adipogenic transcription factors, such as CCAAT/enhancer-binding protein $\alpha, \beta$, and $\delta(\operatorname{Cebp} \alpha, C e b p \beta$, and $C e b p \delta$ ), was shown to be lower in SMF-stimulated BMSCs than those in control cells (Fig. 2c-e). Moreover, the mRNA levels of Ppary adipogenic marker and those of its downstream targets, adiponectin, cluster of differentiation 36 (Cd36), and fatty acid binding protein 4 (Fabp4) (Fig. 2f-i), were demonstrated to be markedly decreased in SMFs-treated BMSCs compared with iron control $(0 \mathrm{~T})$. In contrast, high intensity SMF $(0.6 \mathrm{~T})$ displayed a more apparent inhibitory effect on BMSC differentiation toward adipocytes than lower intensities (0.2 and 0.4 T; Fig. 2a-f).

\section{Moderate SMFs suppressed PPARY-mediated signaling in BMSCs upon adipogenic differentiation}

RNA profile analysis also revealed that some adipogenic transcription factors (Cebp $\alpha, C e b p \beta, C e b p \delta$, and Ppary) and adipocyte marker genes (CD36, Fabp4, Igfbp2, Scd1,
Fasn, Lpi, Mgst3, and Lep) were downregulated in $0.6 \mathrm{~T}$ SMF-stimulated BMSCs compared with those in unchallenged BMSCs (Fig. 3a). The downregulation of the Ppary and Fabp4 genes was further validated in SMFstimulated BMSCs by western blot analysis (Fig. 3b). To correlate the differentially expressed genes with biological functions, we analyzed the functional bias of the differentially expressed genes according to Gene Ontology (GO) enrichment. Our results revealed that SMF altered many metabolic processes in BMSCs, including peptide biosynthetic process, translation, ATP metabolic process, purine ribonucleoside metabolic process, and nucleoside metabolic process (Fig. 3c). Gene-set enrichment analysis (GSEA) showed that PPAR $\gamma$-positively correlated genes were remarkably enriched in iron control-treated BMSCs, compared with those in SMFexposed cells (false discovery rate $($ FDR) $q$ value $=0.009$ ) (Fig. 3d).

\section{Moderate SMFs promoted osteogenic differentiation of murine BMSCs}

To investigate whether exposure to SMF might affect the osteogenic differentiation of BMSCs, we examined the phenotypical changes of SMFs-challenged BMSCs cultured in osteogenesis induction medium. After osteogenic induction, we found that moderate SMFs enhanced the production of ALP, an early marker of osteogenesis in BMSCs in a dose-dependent manner (Fig. 4a, b). Consistently, ALS staining and quantification of ALS absorption revealed a significant enhancement of osteogenesis in SMF-stimulated BMSCs compared with controls (Fig. 4c, d). Moreover, the mRNA levels of the key osteogenic transcription factors Runx2 and osterix (Osx) (Fig. 4e, f) and those of coll $\alpha 1, \operatorname{col} 1 \alpha 2, A l p$, and Spp1 osteogenic marker genes (Fig. $4 \mathrm{~g}-\mathrm{j}$ ) were demonstrated to be increased in SMF-exposed BMSCs in a dose-dependent fashion. These results suggested that SMFs promoted osteoblast differentiation of BMSCs.

\section{Moderate SMFs facilitated BMSC differentiation to osteoblasts via activating the Runx2 signaling pathway}

RNA-seq analysis uncovered that the osteogenic transcription factor Runx2 and the osteoblast markers

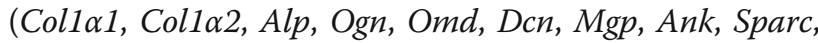
Smpd3, Bgn, and Matn4) were also notably upregulated in SMF-exposed BMSCs cultured in osteogenesis induction medium, as compared with those in control BMSCs (Fig. 5a). Consistent with the mRNA expression results obtained by qPCR and RNA-seq, western blot analysis also showed an increase in the protein expression of the two key osteogenic markers, RUNX2 and ALP, in SMFexposed BMSCs (Fig. 5b). Moreover, GO analysis showed that, upon osteogenic stimulation, SMF altered the gene expression associated with the development of 

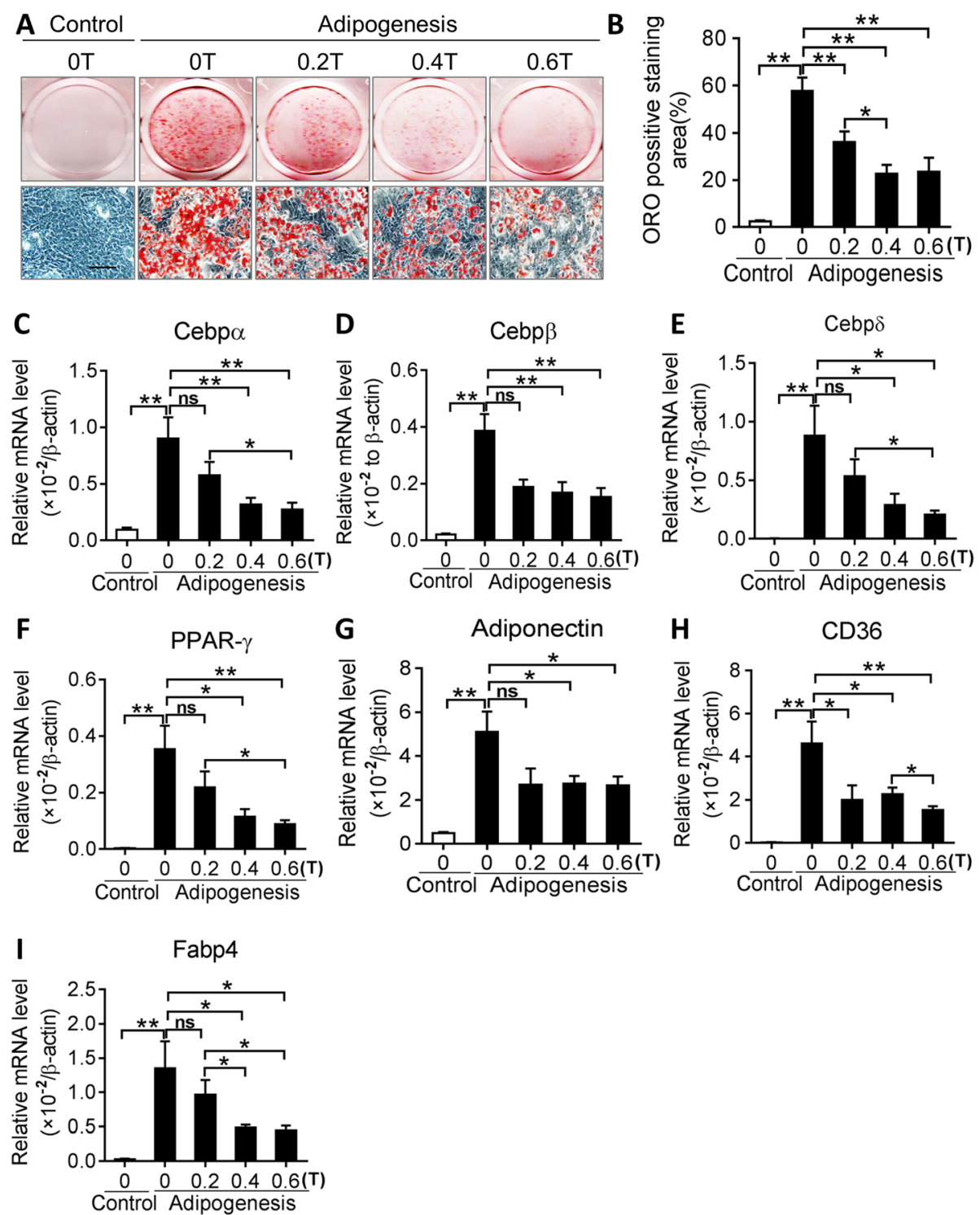

Fig. 2 SMF suppresses adipogenic differentiation of bone marrow-derived mesenchymal stem cells (BMSCs). a Representative images of oil red $O$ (ORO) staining of lipids in BMSCs cultured in adipogenic medium and treated with gradient SMFs $(0,0.2,0.4$, and $0.6 \mathrm{~T})$ for 14 days. Scale bar, $100 \mu \mathrm{m}$. b Quantification of the ORO-positive staining area. ${ }^{*} P<0.05,{ }^{* *} P<0.01$, as indicated. $n=4$ per group. c-i Expression of adipogenic transcription factors $(\mathbf{c}-\mathbf{f})$ and marker genes $(\mathbf{g}-\mathbf{i})$ in BMSCs grown in adipogenesis induction medium and treated with gradient SMFs. ${ }^{*} P<0.05$, ${ }^{*} P<0.01$, as indicated. $n=8-10$ per group. ns=not significant

the skeletal system, metabolic process of collagen, catabolic process of lipids, and others (Fig. 5c). Finally, GSEA analysis revealed that RUNX2 positively correlated genes were notably enriched in SMF-exposed BMSCs $(0.6 \mathrm{~T})$, compared with control cells (0 T) (FDR $q$ value $=0.034)($ Fig. $5 \mathrm{~d})$.

\section{Moderate SMFs reduced ATRA- or Dex-induced bone loss in mice}

Chronic administration of the active metabolite of vitamin A, ATRA, has been reported to lead to significant bone loss in mice [28]. To explore whether SMFs might exert a preventive role in osteoporosis, ATRAchallenged mice were exposed to SMFs of varying intensities $(0,0.2,0.4$, and $0.6 \mathrm{~T})$. ATRA significantly induced bone loss in mice by decreasing bone density (Fig. 6a-c) and Tb.BV/TV and Tb.N (Fig. 6d, e), thus increasing Tb.Sp (Fig. 6f) without markedly influencing trabecular thickness (Fig. 6g). Consistent with the micro-CT images (Fig. 6a, b), histological analysis showed that ATRA promoted the accumulation of adipocytes in the bone marrow (Fig. $6 \mathrm{~h}-\mathrm{j}$ ) and reduced OCN-positive osteoblasts on both the trabecular and endosteal bone surfaces (Fig. 6k, l) in mice. However, SMFs were shown to 


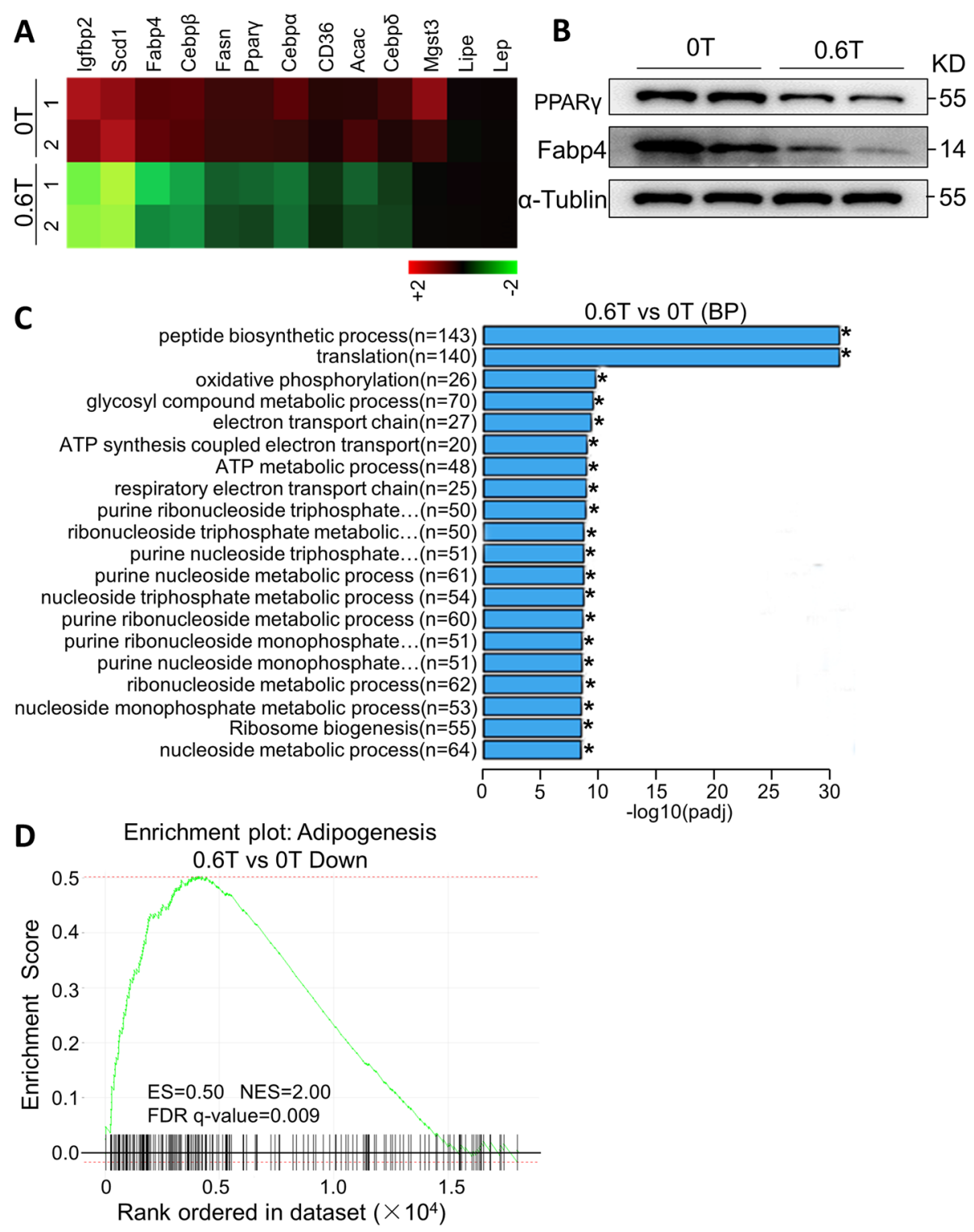

Fig. 3 SMF inhibits peroxisome proliferator-activated receptor $\gamma$ (PPARY)-mediated signaling in BMSCs cultured in adipogenic medium. a Heatmap of the mRNA expression of downregulated adipogenic genes, as detected by deep sequencing, in BMSCs grown in adipogenic medium and stimulated with 0.6 T SMF for $48 \mathrm{~h}$ (fold change $>2$, false discovery rate $<0.20$ ). b Western blot analysis of PPARY and FABP4 in SMFexposed BMSCs cultured in adipogenic medium. c Gene Ontology (GO) pathway enrichment analyses of significantly downregulated genes in SMF-exposed BMSCs cultured in adipogenic medium. Top 20 enriched pathways are shown. ${ }^{*} P<0.05$. $\mathbf{d}$ Gene set enrichment analysis (GSEA) indicates that PPARY-positively correlated genes are significantly reduced in SMF-exposed BMSCs compared with those in control cells

notably attenuate the ATRA-induced bone loss in mice by increasing bone density and the total trabecular ratio, reducing the deposition of adipocytes in the bone marrow, and inducing osteoblast regeneration in mice (Fig. 6a-l). Moreover, this effect was noted to be occurring in an SMF intensity-dependent fashion.

We also tested the effects of SMF intervention on Dex-induced bone loss in mice. As shown in Fig. 7a-l, SMFs significantly prevented Dex-induced bone loss in mice by increasing bone density and the total trabecular ratio, reducing the deposition of adipocytes in the bone marrow and inducing osteoblast regeneration in mice in an intensity-dependent manner.

\section{Discussion}

In this study, we stimulated BMSCs during adipogenic and osteogenic differentiation with different intensities of SMFs $(0,0.2,0.4$, and $0.6 \mathrm{~T})$ and found that SMFs promoted osteoblastic differentiation but inhibited adipogenic differentiation of BMSCs in an intensity- 

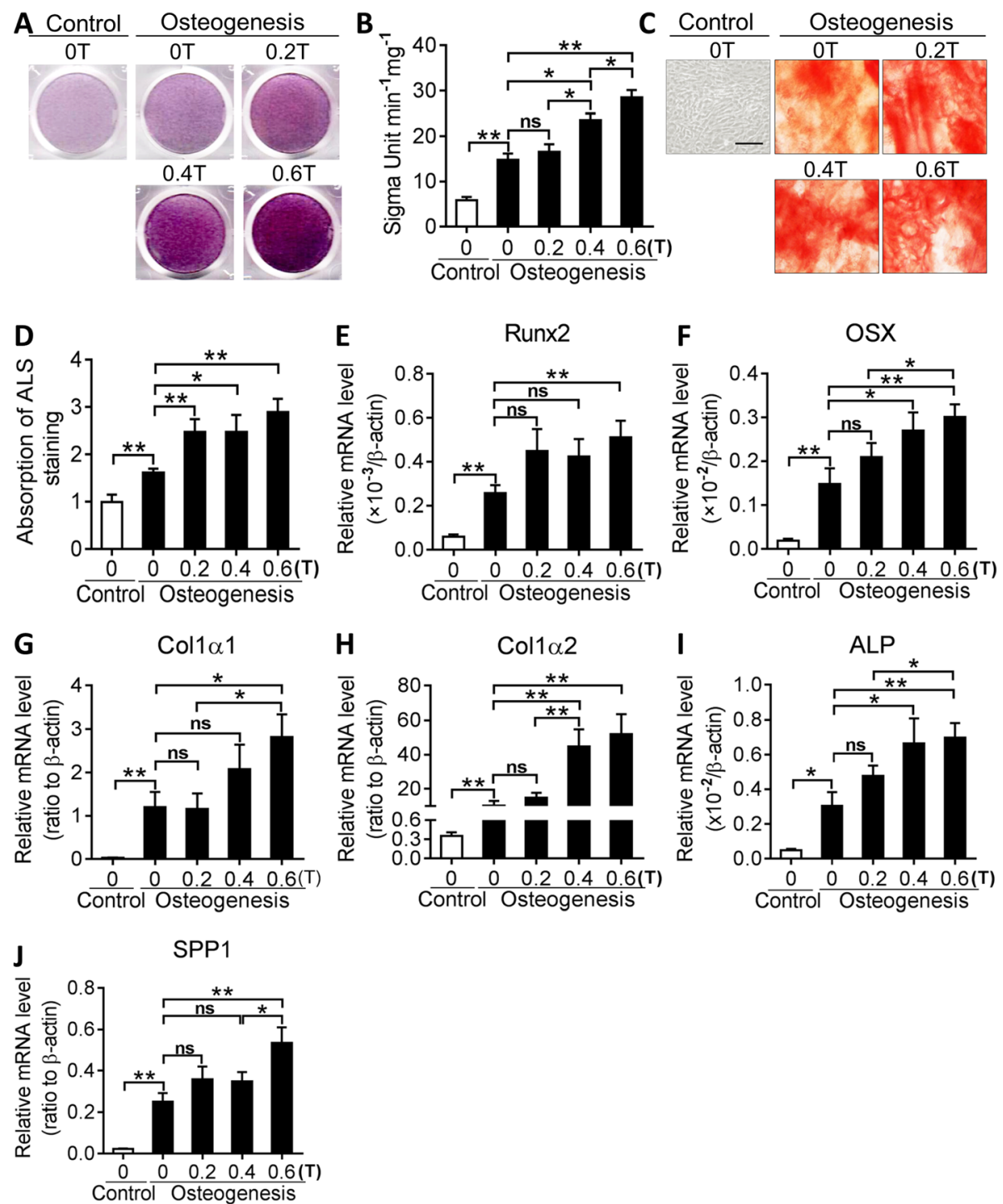

Fig. 4 SMFs promote osteogenic differentiation of BMSCs. a Representative images of alkaline phosphatase (ALP) staining of BMSCS cultured in osteogenic medium and treated with gradient SMF for 3 days. Scale bar, $100 \mu \mathrm{m}$. b Detection of ALP activity. ${ }^{*} P<0.05,{ }^{* *} P<0.01$ vs control or 0 T group. $n=4$ per group. $\mathbf{c}$, $\mathbf{d}$ Representative images of alizarin red S (ALS) staining (c) and quantification of matrix mineralization by ALS absorption (d) in BMSCs grown in osteogenesis induction medium and stimulated with gradient SMF for 21 days. Scale bar, $100 \mu \mathrm{m}$. ${ }^{*} P<0.05$, ${ }^{*} P<0.01$, as indicated. $n=4$ per group. e-j Expression of key osteogenic transcription factors (Runx2 and Ost) (e and $\mathbf{f}$ ) and osteoblast marker genes (Col1a1, Col1a2, Alp, and Spp 1) ( $\mathbf{g}-\mathbf{j})$ in BMSCs grown in osteogenesis induction medium and treated with gradient SMF. ${ }^{*} P<0.05,{ }^{* *} P<$ 0.01 , as indicated. $n=8-10$ per group. ns=not significant

dependent manner. Whole genomic RNA-seq analysis demonstrated that SMFs decreased PPAR $\gamma$-driven gene expression but increased RUNX2-driven gene transcription in BMSCs. Moreover, SMFs markedly alleviated bone mass loss induced by either Dex or ATRA in mice. Thus, our study reveals the therapeutic potential of moderate-intensity SMFs in osteoporosis.

Magnetic fields are known to modulate the behavior of stem cells through multiple routes [31]. They are known to reduce inflammation, facilitate wound healing, and increase blood circulation [32]. In addition, magnetic field therapy has been approved for the management of pain and edema in superficial tissue inflammation by FDA [20]. Extremely low-frequency magnetic fields have been shown to influence cell proliferation by activation of $\mathrm{Na}^{+} / \mathrm{K}^{+}$[33] and $\mathrm{Ca}^{2+}$ [34] channels. SMF has been commonly used in clinical practice as a tool, such as in magnetic resonance imaging (MRI). Moderate-intensity SMFs (1 $\mathrm{mT}$ to $1 \mathrm{~T})$ were reported to enhance proliferation, migration, and dentinogenesis of dental pulp stem cells by activating the p38 mitogen-activated protein kinase pathway [35-37] and to induce osteo/odontogenesis 

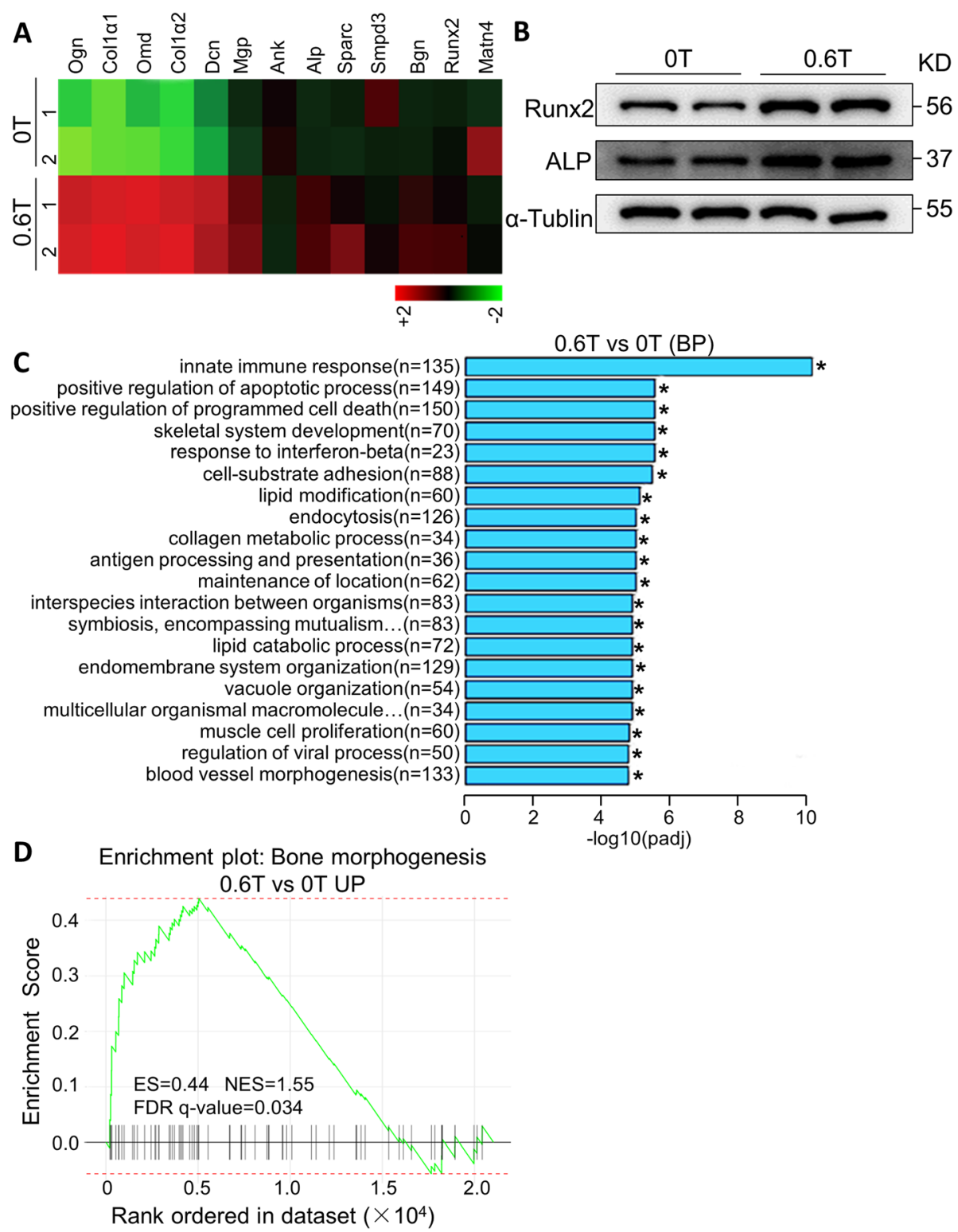

Fig. 5 SMF activates RUNX2-mediated signaling in BMSCs in osteogenesis differentiation medium. a Heatmap of mRNA expression of osteogenic genes, as detected by deep sequencing, in BMSCs cultured in osteogenesis differentiation medium and stimulated with $0.6 \mathrm{~T} \mathrm{SMF}$ for $48 \mathrm{~h}$ (fold change $>2$, false discovery rate $<0.20$ ). $\mathbf{b}$ Western blot analysis of RUNX2 and ALP in SMF-exposed BMSCs cultured in osteogenesis differentiation medium. c GO pathway enrichment analyses of significantly upregulated genes in SMF-exposed BMSCs grown in osteogenesis differentiation medium. Top 20 enriched pathways are shown. ${ }^{*}<0.05$. d GSEA indicates that osteogenesis-positively correlated genes are significantly enriched in the SMF-exposed BMSCs compared with those in control cells

and mineralization in dental pulp stem cells [37, 38]. Similarly, moderate-intensity SMF also promoted neuronal differentiation in fetal rat brain neural progenitor cells [39] and induced the proliferation and osteoblastic differentiation of BMSCs [40, 41].

BMSCs are known to differentiate into adipocytes instead of osteoblasts with aging, leading to the occurrence of osteoporosis, which is characterized by bone loss and progressive accumulation of fat $[42,43]$. Here, we demonstrated that SMFs repressed adipogenic differentiation but promoted osteogenic differentiation of BMSCs in an intensity-dependent manner by suppressing the PPARy signaling pathway and activating the RUNX2 signaling pathway. Their capacity to differentiate into osteoblastic and adipogenic lineages is dependent on various signaling pathways and key transcription factors [44]. Activation of Runx2 and Osx has been found to promote osteogenic differentiation and inhibit adipogenic differentiation of BMSCs [45]. Conversely, Cebp $\alpha, C e b p \beta$, and Ppary have been reported to drive adipogenesis and disrupt 

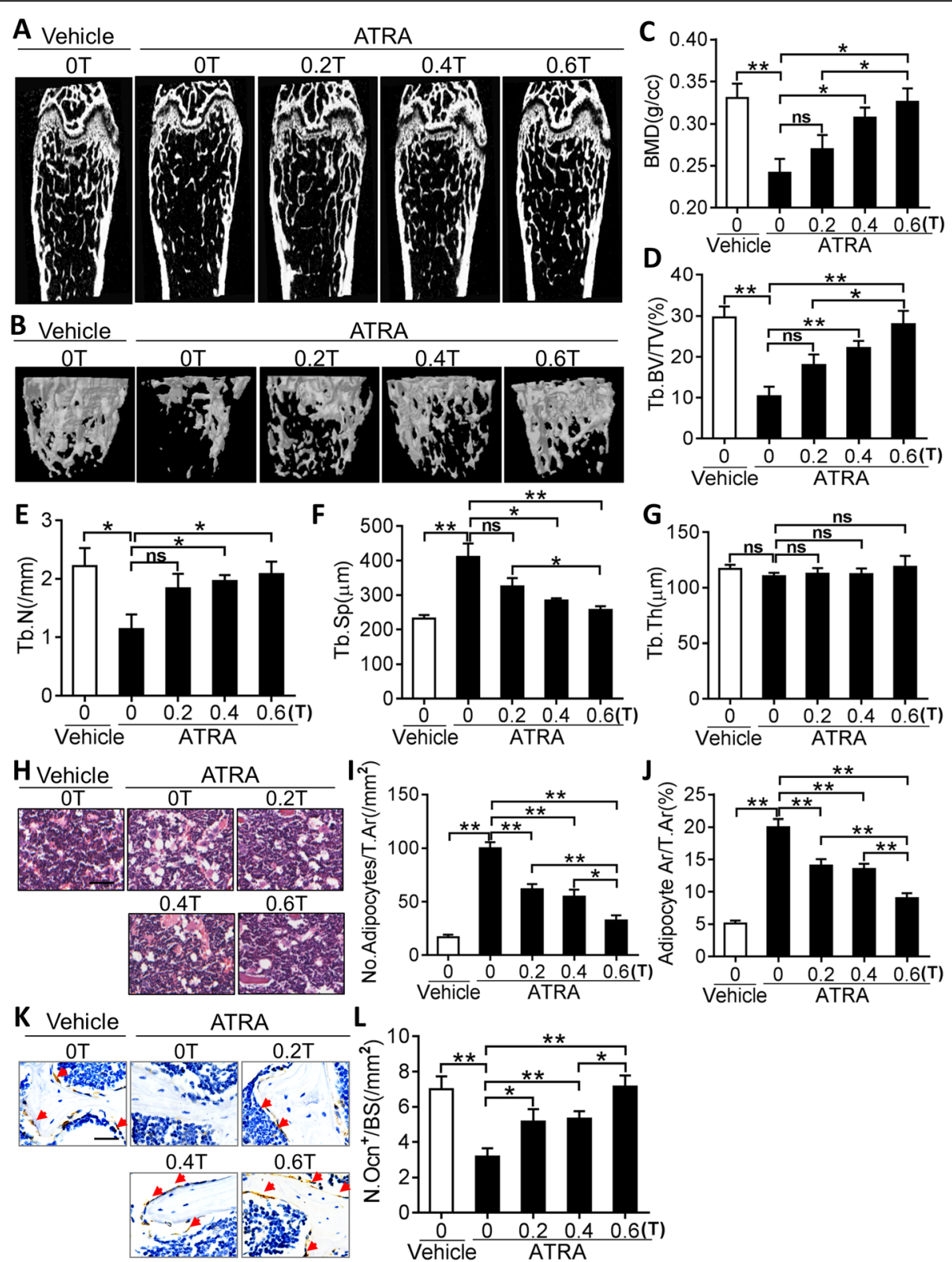

Fig. 6 SMFs reduces all-trans retinoic acid (ATRA)-induced bone loss in mice. a, b Representative two-dimensional (2D) (a) and three-dimensional (3D) (b) microcomputed tomography (micro-CT) images of femurs from ATRA-treated mice with gradient SMF exposure for 21 days. $\mathbf{c}-\mathbf{g}$ Quantitative micro-CT analysis of bone mineral density (BMD) (c), trabecular bone volume per tissue volume (Tb.BV/TV) (d), trabecular number (Tb.N) (e), trabecular separation (Tb.Sp) (f), and trabecular thickness (Tb.Th) $(\mathbf{g})$ in SMF-exposed mice after ATRA injection. ${ }^{*} P<0.05$, ** $P<0.01$, as indicated. $n=4-5$ per group. $\mathbf{h}-\mathbf{j}$ Representative images of H\&E staining (h) with quantification of number (i) and area (j) of adipocytes in distal femurs. Scale bar, $100 \mu \mathrm{m} . n=5$ per group. k-I Representative images of osteocalcin (OCN) immunohistochemical staining (k) with quantification of number (I) of osteoblasts in distal femurs. Scale bar, $100 \mu \mathrm{m} .{ }^{*} P<0.05,{ }^{* *} P<0.01$, as indicated. $n=5$ per group. ns=not significant

osteogenic differentiation of BMSCs [46, 47]. We demonstrated that moderate-intensity SMFs notably inhibited the expression of the Cebp $\beta$ and Ppary adipogenic transcription factors in BMSCs cultured in adipogenesis induction medium but upregulated the Runx2 osteogenic transcription factor and its downstream targeted genes in BMSCs upon osteogenic stimulation. Bioinformatics analysis showed that SMFs altered the gene expression associated with the metabolism of fat in adipogenic medium-cultured BMSCs and promoted the expression of genes associated with skeletal development and osteoblast differentiation in osteogenic medium-cultured BMSCs.

Because SMFs are time-independent fields whose intensity can be spatially dependent, they are able to freely penetrate the biological tissues [48]. The biological effects of SMFs are known to be related to the dosing 

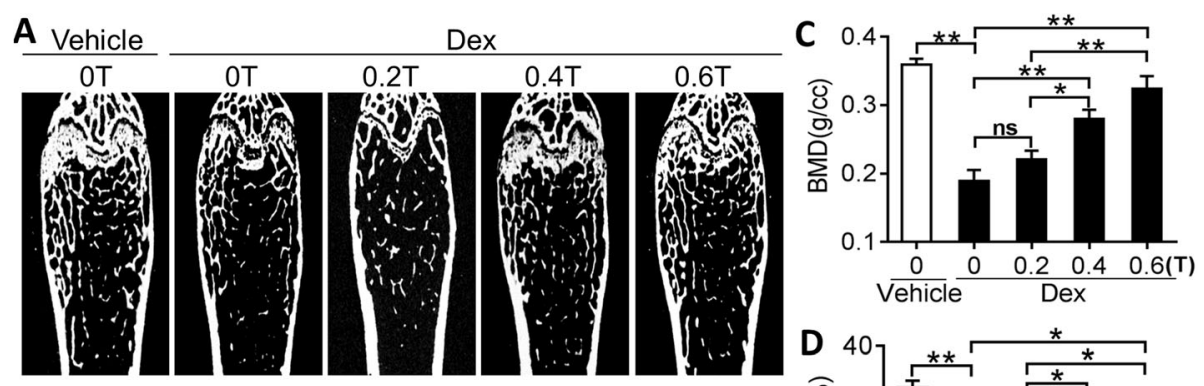
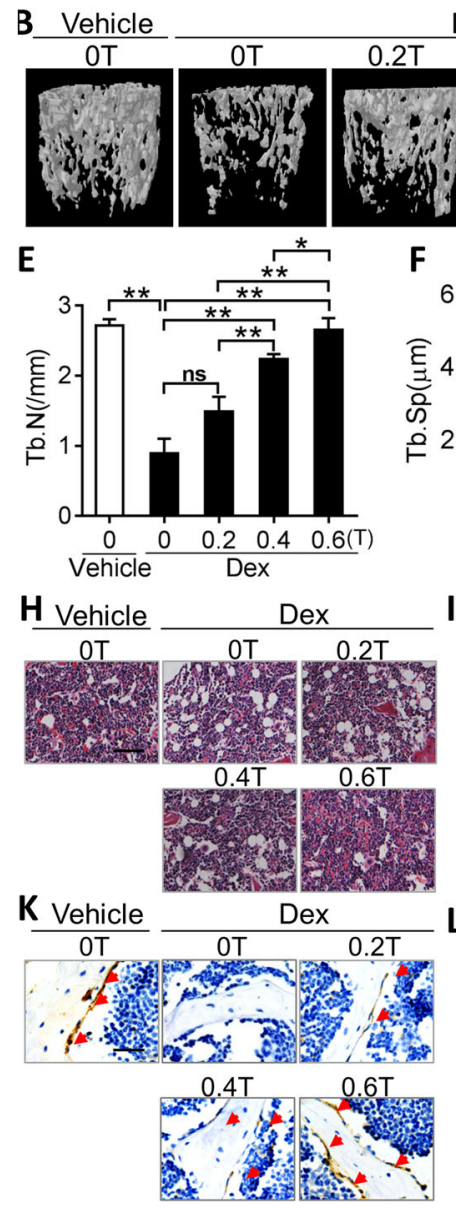

$\mathbf{F}$
Dex
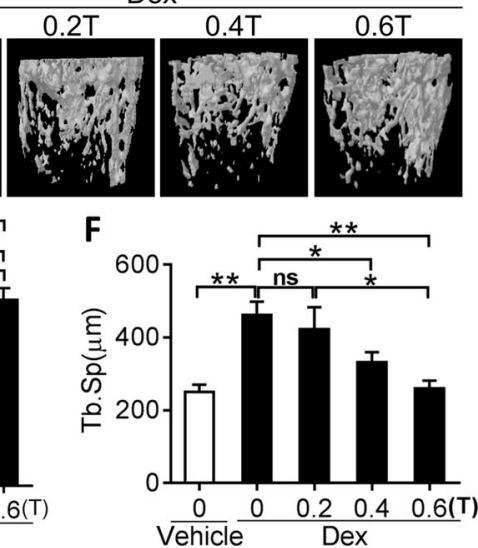

I

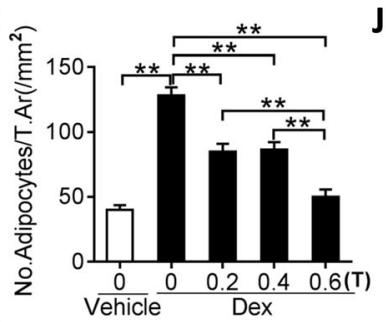

.

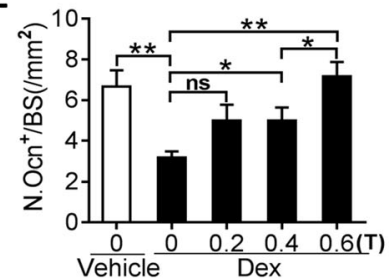

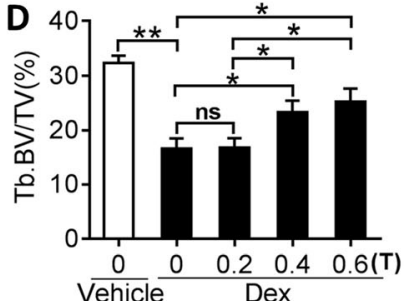

G
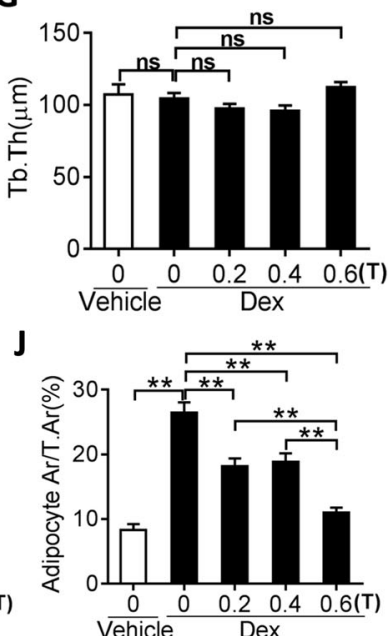

Fig. 7 SMFs reduces dexamethasone (Dex)-stimulated osteoporosis in mice. a, b Representative 2D (a) and 3D (b) micro-CT images of femurs from control and Dex-treated mice with gradient SMF stimulation for 3 months. c-g Quantitative micro-CT analysis of BMD (c), BV/TV (d), Tb.N (e), Tb.Sp (f), and Tb.Th $(\mathbf{g})$ in SMF-exposed mice after Dex injection. ${ }^{*} P<0.05$, ${ }^{*} P<0.01$, as indicated. $n=4-5$ per group. $\mathbf{h}-\mathbf{j}$ H\&E staining (h) and quantification of number (i) and area (j) of adipocytes in distal femurs. Scale bar, $100 \mu \mathrm{m} . n=6$ per group. $\mathbf{k}-\mathbf{I}$ Representative images of OCN immunohistochemical staining (k) and quantification of number (I) of osteoblasts in distal femurs. Scale bar, $100 \mu \mathrm{m}$. ${ }^{*} P<0.05,{ }^{* *} P<0.01$, as indicated. $n=5$ per group. $n s=$ not significant

regimen, target tissue, magnet characteristics, and the magnet support device [49]. Mechanistically, SMF has been shown to be able to directly regulate the cell shape and plasma membrane structure [50], interact with magnetic materials found in tissues [51], and modulate intracellular levels of reactive oxygen/nitrogen species [52]. Additionally, SMFs have also been reported to exert their effects by enhancing synthesis and secretion of membrane-derived microvesicles (MVs), mediating drug delivery and perhaps by inducing mitophagy [31, 53, 54]. Recently, an iron-sulfur cluster protein, called ironsulfur cluster assembly protein 1 , was identified and validated in mammalian cells as a magnetic sensor $[55,56]$. However, further studies are required to investigate how SMFs regulate the RUNX2/PPAR $\gamma$-mediated signaling pathways during BMSC differentiation.

Glucocorticoids are widely prescribed for the treatment of autoimmune and inflammatory diseases; 
however, long-term treatment in the clinical setting has been shown to frequently cause osteoporosis. We also showed here that moderate SMFs promoted BMSC differentiation to osteoblasts and prevented ATRA- and Dex-induced bone loss in mice. Moreover, others have also reported that SMFs markedly accelerate the healing of osteotomized femur and promote bone regeneration in rats $[23,57]$. Therefore, SMF might be helpful for the prevention and treatment of osteoporosis.

Both SMF and electromagnetic fields (EMF) including pulsed electromagnetic fields (PEMF) can substantially facilitate bone healing. For instance, EMFs positively regulates osteogenic lineage commitment of BMSCs [58]. Similarly, low-frequency PEMFs facilitate bone repair by promoting osteoblast proliferation and osteogenic differentiation of BMSCs [59]. Thus, as a noninvasive, effective, and clinical safety treatment, EMF therapies have been commercially used to promote bone un-united fracture healing [59-62] and other skeletal disorders [63]. Compared to EMFs, SMFs appear more convenient without additional electrical devices, which avoids electric or heat hazard to surrounding tissue [64]. Importantly, SMF stimulation is suitable for long-term topical treatment [40, 65]. In this study, we demonstrate the moderateintensity SMFs ranging from $0.2 \mathrm{~T}$ to $0.6 \mathrm{~T}$ induce bone repair in mice in a dose-dependent manner.

\section{Conclusions}

In summary, SMFs protected against ATRA- or Dexinduced osteoporosis in mice by promoting the RUNX2mediated osteogenic differentiation and suppressing the PPAR $\gamma$-mediated lipogenic differentiation of BMSCs. These results suggested that SMF-based magnetotherapy might be beneficial for patients with osteoporosis.

\section{Highlights}

- Moderate-intensity SMF promotes osteogenic differentiation of BMSCs.

- Moderate-intensity SMF suppresses lipogenic differentiation of BMSCs.

- Moderate-intensity SMF reduces bone mass loss induced by either dexamethasone or all-trans retinoic acid in mice.

\section{Supplementary Information}

Supplementary information accompanies this paper at https://doi.org/10. 1186/s13287-020-02004-y.

Additional file 1: sFig. 1. The identification of BMSCs by flow cytometry.

Additional file 2: Supplementary Table 1. Real time-PCR primer sequences.

\section{Abbreviations}

ALS: Alizarin red S; ALP: Alkaline phosphatase; ATRA: All-trans retinoic acid; ASCs: Adipose-derived stem cells; BMSCs: Bone marrow-derived mesenchymal stem cells; BMD: Bone mineral density; Cd36: Cluster of differentiation 36; Dex: Dexamethasone; Fabp4: Fatty acid binding protein 4; GO: Gene ontology; GSEA: Gene-set enrichment analysis; ORO: Oil red O;

OCN: Osteocalcin; Osx: Osterix; SMFs: Static magnetic fields; PEMF: Pulsed electromagnetic fields; Tb.BV/TV: Trabecular bone volume per tissue volume; Tb.N: Trabecular number; Tb.Sp: Trabecular separation

\section{Acknowledgements \\ Ying Yu is a fellow of the Jiangsu Collaborative Innovation Center for Cardiovascular Disease Translational Medicine.}

\section{Authors' contributions}

G. C., Z. F., and Y. Y. designed the research. Y. Z., B. T., Q. L., W. S., Y. L., and Y. W. performed the research. Y. L., L. Z., Y. F., and X. Z. analyzed the data. G. C. wrote the manuscript. Y. Y. revised the manuscript. The authors read and approved the final manuscript.

\section{Funding}

This work was supported by the National Natural Science Foundation of China (82003827) and China Postdoctoral Science Foundation (2019 M661040).

\section{Availability of data and materials}

All data needed to evaluate the conclusions in the paper are present in the paper and/or the Supplementary Materials. Additional data related to this paper may be requested from the authors.

\section{Ethics approval and consent to participate}

Mice were used in accordance with the federal guidelines and approved by the Animal Ethical and Welfare Committee of Tianjin Medical University (approval number SCXK (Jin): 2019-004).

Consent for publication

Not applicable.

Competing interests

The authors declare that they have no competing interests.

\section{Author details}

${ }^{1}$ Department of Pharmacology, Tianjin Key Laboratory of Inflammatory Biology, The Province and Ministry Co-sponsored Collaborative Innovation Center for Medical Epigenetics, School of Basic Medical Sciences, Tianjin Medical University, Tianjin 300070, China. ${ }^{2}$ Department of Orthopedics, Tianjin Medical University General Hospital, Tianjin 300070, China. ${ }^{3}$ High Magnetic Field Laboratory, Key Laboratory of High Magnetic Field and Ion Beam Physical Biology, Hefei Institutes of Physical Science, Chinese Academy of Sciences, Hefei 230031, China. ${ }^{4}$ Heye Health Industrial Research Institute of Zhejiang Heye Health Technology, Anji 313300, Zhejiang, China.

Received: 6 July 2020 Accepted: 29 October 2020

Published online: 16 November 2020

References

1. Raisz LG. Pathogenesis of osteoporosis: concepts, conflicts, and prospects. J Clin Invest. 2005;115:3318-25.

2. Masi L. Epidemiology of osteoporosis, Clin Cases Mineral Bone Metabolism. 2008;5:11-3.

3. Pittenger MF, Mackay AM, Beck SC, Jaiswal RK, Douglas R, Mosca JD, Moorman MA, Simonetti DW, Craig S, Marshak DR. Multilineage potential of adult human mesenchymal stem cells. Science. 1999;284:143-7.

4. Shafaei $\mathrm{H}$, Kalarestaghi H. Adipose-derived stem cells: an appropriate selection for osteogenic differentiation. J Cell Physiol. 2020;235:8371-86.

5. Niemeyer P, Fechner K, Milz S, Richter W, Suedkamp NP, Mehlhorn AT, Pearce S, Kasten P. Comparison of mesenchymal stem cells from bone marrow and adipose tissue for bone regeneration in a critical size defect of the sheep tibia and the influence of platelet-rich plasma. Biomaterials. 2010; 31:3572-9. 
6. Lotfy A, Salama M, Zahran F, Jones E, Badawy A, Sobh M. Characterization of mesenchymal stem cells derived from rat bone marrow and adipose tissue: a comparative study. Int J Stem Cells. 2014;7:135-42.

7. McDonough AK, Rosenthal RS, Cao X, Saag KG. The effect of thiazolidinediones on BMD and osteoporosis. Nat Clin Pract Endocrinol Metab. 2008:4:507-13.

8. Nishikawa K, Nakashima T, Takeda S, Isogai M, Hamada M, Kimura A, Kodama T, Yamaguchi A, Owen MJ, Takahashi S, Takayanagi H. Maf promotes osteoblast differentiation in mice by mediating the agerelated switch in mesenchymal cell differentiation. J Clin Invest. 2010; 120:3455-65.

9. Marycz K, Tomaszewski KA, Kornicka K, Henry BM, Wronski S, Tarasiuk J, Maredziak M. Metformin decreases reactive oxygen species, enhances osteogenic properties of adipose-derived multipotent mesenchymal stem cells in vitro, and increases bone density in vivo. Oxidative Med Cell Longev. 2016;2016:9785890.

10. Tao ZS, Lu HL, Ma NF, Zhang RT, Li Y, Yang M, Xu HG. Rapamycin could increase the effects of melatonin against age-dependent bone loss. Zeitschrift fur Gerontologie und Geriatrie. 2020;53:671-8.

11. Maredziak M, Smieszek A, Chrzastek K, Basinska K, Marycz K. Physical activity increases the total number of bone-marrow-derived mesenchymal stem cells, enhances their osteogenic potential, and inhibits their adipogenic properties. Stem Cells Int. 2015;2015:379093.

12. Marycz K, Mierzejewska K, Smieszek A, Suszynska E, Malicka I, Kucia M, Ratajczak MZ. Endurance exercise mobilizes developmentally early stem cells into peripheral blood and increases their number in bone marrow: implications for tissue regeneration. Stem Cells Int. 2016;2016:5756901.

13. Zwolinska J, Gasior M, Sniezek E, Kwolek A. The use of magnetic fields in treatment of patients with rheumatoid arthritis. Review of the literature. Reumatologia. 2016;54:201-6.

14. Vergallo C, Dini L, Szamosvolgyi Z, Tenuzzo BA, Carata E, Panzarini E, Laszlo JF. In vitro analysis of the anti-inflammatory effect of inhomogeneous static magnetic field-exposure on human macrophages and lymphocytes. PLoS One. 2013;8:e72374.

15. Morris CE, Skalak TC. Acute exposure to a moderate strength static magnetic field reduces edema formation in rats. Am J Phys Heart Circ Phys. 2008;294:H50-7.

16. Xu S, Okano H, Ohkubo C. Acute effects of whole-body exposure to static magnetic fields and $50-\mathrm{Hz}$ electromagnetic fields on muscle microcirculation in anesthetized mice. Bioelectrochemistry. 2001;53: 127-35.

17. Gmitrov J, Ohkubo C, Okano H. Effect of $0.25 \mathrm{~T}$ static magnetic field on microcirculation in rabbits. Bioelectromagnetics. 2002;23:224-9.

18. Harlow T, Greaves C, White A, Brown L, Hart A, Ernst E. Randomised controlled trial of magnetic bracelets for relieving pain in osteoarthritis of the hip and knee. Bmj. 2004;329:1450-4.

19. Shang W, Chen G, Li Y, Zhuo Y, Wang Y, Fang Z, Yu Y, Ren H. Static magnetic field accelerates diabetic wound healing by facilitating resolution of inflammation. J Diabetes Res. 2019:2019:5641271.

20. Markov MS. Expanding use of pulsed electromagnetic field therapies. Electromagnetic Biol Med. 2007;26:257-74

21. Meng J, Xiao B, Zhang Y, Liu J, Xue H, Lei J, Kong H, Huang Y, Jin Z, Gu N, Xu H. Super-paramagnetic responsive nanofibrous scaffolds under static magnetic field enhance osteogenesis for bone repair in vivo. Sci Rep. 2013;3:2655.

22. Jaberi FM, Keshtgar S, Tavakkoli A, Pishva E, Geramizadeh B, Tanideh N, Jaberi MM. A moderate-intensity static magnetic field enhances repair of cartilage damage in rabbits. Arch Med Res. 2011;42:268-73.

23. Xu S, Okano H, Tomita N, Ikada Y. Recovery effects of a $180 \mathrm{mT}$ static magnetic field on bone mineral density of osteoporotic lumbar vertebrae in ovariectomized rats. Evidence-Based Complementary Alternative Med. 2011; 2011:620984.

24. Zhang H, Gan L, Zhu X, Wang J, Han L, Cheng P, Jing D, Zhang X, Shan Q. Moderate-intensity $4 \mathrm{mT}$ static magnetic fields prevent bone architectural deterioration and strength reduction by stimulating bone formation in streptozotocin-treated diabetic rats. Bone. 2018;107:36-44.

25. Li Q, Liao Z, Gu L, Zhang L, Zhang L, Tian X, Li J, Fang Z, Zhang X. Moderate intensity static magnetic fields prevent thrombus formation in rats and mice. Bioelectromagnetics. 2020;41:52-62.

26. Soleimani M, Nadri S. A protocol for isolation and culture of mesenchymal stem cells from mouse bone marrow. Nat Protoc. 2009;4:102-6.
27. Liu Y, Berendsen AD, Jia S, Lotinun S, Baron R, Ferrara N, Olsen BR. Intracellular VEGF regulates the balance between osteoblast and adipocyte differentiation. J Clin Invest. 2012;122:3101-13.

28. Broulik PD, Raska I, Broulikova K. Prolonged overdose of all-trans retinoic acid enhances bone sensitivity in castrated mice. Nutrition. 2013:29:1166-9.

29. Yao W, Dai W, Jiang L, Lay EY, Zhong Z, Ritchie RO, Li X, Ke H, Lane NE. Sclerostin-antibody treatment of glucocorticoid-induced osteoporosis maintained bone mass and strength. Osteoporos Int. 2016;27:283-94.

30. Li CJ, Xiao Y, Yang M, Su T, Sun X, Guo Q, Huang Y, Luo XH. Long noncoding RNA Bmncr regulates mesenchymal stem cell fate during skeletal aging. J Clin Invest. 2018;128:5251-66.

31. Marycz K, Kornicka K, Rocken M. Static magnetic field (SMF) as a regulator of stem cell fate - new perspectives in regenerative medicine arising from an underestimated tool. Stem Cell Rev Rep. 2018;14:785-92.

32. Markov M. XXIst century magnetotherapy. Electromagnetic Biol Med. 2015; 34:190-6.

33. Yan J, Dong L, Zhang B, Qi N. Effects of extremely low-frequency magnetic field on growth and differentiation of human mesenchymal stem cells. Electromagnetic Biol Med. 2010;29:165-76.

34. Boles LC, Lohmann KJ. True navigation and magnetic maps in spiny lobsters. Nature. 2003;421:60-3.

35. Lew WZ, Feng SW, Lin CT, Huang HM. Use of 0.4-Tesla static magnetic field to promote reparative dentine formation of dental pulp stem cells through activation of p38 MAPK signalling pathway. Int Endod J. 2019; 52:28-43.

36. Lew WZ, Huang YC, Huang KY, Lin CT, Tsai MT, Huang HM. Static magnetic fields enhance dental pulp stem cell proliferation by activating the p38 mitogen-activated protein kinase pathway as its putative mechanism. J Tissue Eng Regen Med. 2018;12:19-29.

37. Xia Y, Chen H, Zhao Y, Zhang F, Li X, Wang L, Weir MD, Ma J, Reynolds MA, Gu N, Xu HHK. Novel magnetic calcium phosphate-stem cell construct with magnetic field enhances osteogenic differentiation and bone tissue engineering. Mater Sci Eng C Mater Biol Appl. 2019;98:30-41.

38. Zheng $L$, Zhang $L$, Chen $L$, Jiang J, Zhou X, Wang M, Fan Y. Static magnetic field regulates proliferation, migration, differentiation, and YAP/TAZ activation of human dental pulp stem cells. J Tissue Eng Regen Med. 2018; 12:2029-40.

39. Nakamichi N, Ishioka Y, Hirai T, Ozawa S, Tachibana M, Nakamura N, Takarada T, Yoneda Y. Possible promotion of neuronal differentiation in fetal rat brain neural progenitor cells after sustained exposure to static magnetism. J Neurosci Res. 2009;87:2406-17.

40. Kim EC, Leesungbok R, Lee SW, Lee HW, Park SH, Mah SJ, Ahn SJ. Effects of moderate intensity static magnetic fields on human bone marrow-derived mesenchymal stem cells. Bioelectromagnetics. 2015;36:267-76.

41. He Y, Yu L, Liu J, Li Y, Wu Y, Huang Z, Wu D, Wang H, Wu Z, Qiu G. Enhanced osteogenic differentiation of human bone-derived mesenchymal stem cells in 3-dimensional printed porous titanium scaffolds by static magnetic field through up-regulating Smad4. FASEB J. 2019;33:6069-81.

42. Moerman EJ, Teng K, Lipschitz DA, Lecka-Czernik B. Aging activates adipogenic and suppresses osteogenic programs in mesenchymal marrow stroma/stem cells: the role of PPAR-gamma2 transcription factor and TGFbeta/BMP signaling pathways. Aging Cell. 2004;3:379-89.

43. Riggs BL, Wahner HW, Seeman E, Offord KP, Dunn WL, Mazess RB, Johnson $K A$, Melton $L$ 3rd. Changes in bone mineral density of the proximal femur and spine with aging. Differences between the postmenopausal and senile osteoporosis syndromes. J Clin Invest. 1982;70:716-23.

44. Chen Q, Shou P, Zheng C, Jiang M, Cao G, Yang Q, Cao J, Xie N, Velletri T, Zhang $X$, et al. Fate decision of mesenchymal stem cells: adipocytes or osteoblasts? Cell Death Differ. 2016;23:1128-39.

45. Yuan Z, Li Q, Luo S, Liu Z, Luo D, Zhang B, Zhang D, Rao P, Xiao J. PPARgamma and Wnt signaling in adipogenic and osteogenic differentiation of mesenchymal stem cells. Curr Stem Cell Res Therapy. 2016; 11:216-25.

46. Takada I, Kouzmenko AP, Kato S. Wnt and PPARgamma signaling in osteoblastogenesis and adipogenesis. Nat Rev Rheumatol. 2009;5:442-7.

47. Takada I, Mihara M, Suzawa M, Ohtake F, Kobayashi S, Igarashi M, Youn MY, Takeyama K, Nakamura T, Mezaki Y, et al. A histone lysine methyltransferase activated by non-canonical Wnt signalling suppresses PPAR-gamma transactivation. Nat Cell Biol. 2007;9:1273-85. 
48. Hashish AH, El-Missiry MA, Abdelkader HI, Abou-Saleh RH. Assessment of biological changes of continuous whole body exposure to static magnetic field and extremely low frequency electromagnetic fields in mice. Ecotoxicol Environ Saf. 2008;71:895-902.

49. Colbert AP, Wahbeh H, Harling N, Connelly E, Schiffke HC, Forsten C, Gregory WL, Markov MS, Souder JJ, Elmer P, King V. Static magnetic field therapy: a critical review of treatment parameters. Evidence-Based Complementary Alternative Med. 2009;6:133-9.

50. Chionna A, Dwikat M, Panzarini E, Tenuzzo B, Carla EC, Verri T, Pagliara P, Abbro L, Dini L. Cell shape and plasma membrane alterations after static magnetic fields exposure. Eur J Histochem. 2003;47:299-308.

51. Kirschvink JL, Kobayashi-Kirschvink A, Woodford BJ. Magnetite biomineralization in the human brain. Proc Natl Acad Sci U S A. 1992;89:7683-7.

52. Ghodbane S, Lahbib A, Sakly M, Abdelmelek H. Bioeffects of static magnetic fields: oxidative stress, genotoxic effects, and cancer studies. Biomed Res Int. 2013;2013:602987.

53. Maredziak M, Marycz K, Lewandowski D, Siudzinska A, Smieszek A. Static magnetic field enhances synthesis and secretion of membrane-derived microvesicles (MVs) rich in VEGF and BMP-2 in equine adipose-derived stromal cells (EqASCs)-a new approach in veterinary regenerative medicine. In Vitro Cellular Developmental Biol Animal. 2015;51:230-40.

54. Marycz K, Weiss C, Smieszek A, Kornicka K. Evaluation of oxidative stress and mitophagy during adipogenic differentiation of adipose-derived stem cells isolated from equine metabolic syndrome (EMS) horses. Stem Cells Int. 2018;2018:5340756

55. Qin S, Yin H, Yang C, Dou Y, Liu Z, Zhang P, Yu H, Huang Y, Feng J, Hao J, et al. A magnetic protein biocompass. Nat Mater. 2016;15:217-26.

56. Long $X$, Ye J, Zhao D, Zhang SJ. Magnetogenetics: remote non-invasive magnetic activation of neuronal activity with a magnetoreceptor. Science Bulletin. 2015;60:2107-19.

57. Aydin N, Bezer M. The effect of an intramedullary implant with a static magnetic field on the healing of the osteotomised rabbit femur. Int Orthop. 2011;35:135-41.

58. Yang Y, Tao C, Zhao D, Li F, Zhao W, Wu H. EMF acts on rat bone marrow mesenchymal stem cells to promote differentiation to osteoblasts and to inhibit differentiation to adipocytes. Bioelectromagnetics. 2010;31:277-85.

59. Assiotis A, Sachinis NP, Chalidis BE. Pulsed electromagnetic fields for the treatment of tibial delayed unions and nonunions. A prospective clinical study and review of the literature. J Orthopaedic Surg Res. 2012;7:24.

60. Della Bella E, Tschon M, Stagni C, Dallari D, Fini M. Biophysical stimulation for nonunions. J Biol Regul Homeost Agents. 2015;29:25-38.

61. Massari L, Benazzo F, Falez F, Perugia D, Pietrogrande L, Setti S, Osti R, Vaienti E, Ruosi C, Cadossi R. Biophysical stimulation of bone and cartilage: state of the art and future perspectives. Int Orthop. 2019:43:539-51.

62. Hannemann PF, Mommers EH, Schots JP, Brink PR, Poeze M. The effects of low-intensity pulsed ultrasound and pulsed electromagnetic fields bone growth stimulation in acute fractures: a systematic review and meta-analysis of randomized controlled trials. Arch Orthop Trauma Surg. 2014:134:1093-106.

63. Trock DH, Bollet AJ, Markoll R. The effect of pulsed electromagnetic fields in the treatment of osteoarthritis of the knee and cervical spine. Report of randomized, double blind, placebo controlled trials. J Rheumatol. 1994;21: 1903-11.

64. Markov MS. Magnetic field therapy: a review. Electromagnetic Biol Med. 2007:26:1-23.

65. Zhang J, Ding C, Ren L, Zhou Y, Shang P. The effects of static magnetic fields on bone. Prog Biophys Mol Biol. 2014;114:146-52.

\section{Publisher's Note}

Springer Nature remains neutral with regard to jurisdictional claims in published maps and institutional affiliations.

Ready to submit your research? Choose BMC and benefit from:

- fast, convenient online submission

- thorough peer review by experienced researchers in your field

- rapid publication on acceptance

- support for research data, including large and complex data types

- gold Open Access which fosters wider collaboration and increased citations

- maximum visibility for your research: over $100 \mathrm{M}$ website views per year

At BMC, research is always in progress.

Learn more biomedcentral.com/submissions 